\title{
Development of Loop-Mediated Isothermal Amplification (LAMP) Assays for Rapid Detection of Ehrlichia ruminantium
}

Ryo Nakao ${ }^{1}$, Ellen Y Stromdahl ${ }^{2}$, Joseph W Magona ${ }^{1,3}$, Bonto Faburay ${ }^{4,11}$, Boniface Namangala ${ }^{5}$, Imna Malele ${ }^{6}$, Noboru Inoue ${ }^{7}$, Dirk Geysen ${ }^{8}$, Kiichi Kajino ${ }^{1}$, Frans Jongejan ${ }^{9,10}$, Chihiro Sugimoto ${ }^{1 *}$

\begin{abstract}
Background: The rickettsial bacterium Ehrlichia ruminantium is the causative agent of heartwater, a potential zoonotic disease of ruminants transmitted by ticks of the genus Amblyomma. The disease is distributed in nearly all of sub-Saharan Africa and some islands of the Caribbean, from where it threatens the American mainland. This report describes the development of two different loop-mediated isothermal amplification (LAMP) assays for sensitive and specific detection of E. ruminantium.

Results: Two sets of LAMP primers were designed from the pCS20 and sodB genes. The detection limits for each assay were 10 copies for pCS20 and 5 copies for sodB, which is at least 10 times higher than that of the conventional pCS20 PCR assay. DNA amplification was completed within $60 \mathrm{~min}$. The assays detected 16 different isolates of E. ruminantium from geographically distinct countries as well as two attenuated vaccine isolates. No cross-reaction was observed with genetically related Rickettsiales, including zoonotic Ehrlichia species from the USA. LAMP detected more positive samples than conventional PCR but less than real-time PCR, when tested with field samples collected in sub-Saharan countries.
\end{abstract}

Conclusions: Due to its simplicity and specificity, LAMP has the potential for use in resource-poor settings and also for active screening of E. ruminantium in both heartwater-endemic areas and regions that are at risk of contracting the disease.

\section{Background}

The rickettsial bacterium Ehrlichia ruminantium is a causative agent of heartwater, the disease of ruminants transmitted by ticks of the genus Amblyomma [1]. Heartwater is not only responsible for high economic losses in endemic countries [2], but is also suggested to be a potential emerging zoonosis since the PCR and sequence detection of the pathogen's presence in three fatal human cases although the cytological examination and bacterial isolation were not achieved $[3,4]$. The disease is established in nearly all countries of sub-Saharan Africa and some islands of the Caribbean, from where it threatens the American mainland [5]. In the USA, three

\footnotetext{
* Correspondence: sugimoto@czc.hokudai.ac.jp

'Department of Collaboration and Education, Research Center for Zoonosis Control, Hokkaido University, Kita 20, Nishi 10, Kita-ku, Sapporo, Hokkaido 001-0020, Japan

Full list of author information is available at the end of the article
}

Ehrlichia species, namely E. canis, E. chaffeensis, and E. ewingii, are known to exist [6-11]. Recently, Panola Mountain (PM) Ehrlichia, which is closely related to $E$. ruminantium, was discovered as a novel zoonotic Ehrlichia in the state of Georgia [12,13]. Active surveillance using a reliable method which can discriminate E. ruminantium from these other Ehrlichia species is an asset in preventing introduction of heartwater into the USA.

In heartwater endemic countries, conventional diagnosis is based upon clinical signs and microscopic examination of post-mortem brain smears. As a more reliable and sensitive diagnostic method, several PCR-based assays have been developed for the detection of E. ruminantium, including conventional PCR [14-16], nested PCR $[17,18]$, and real-time PCR $[19,20]$. Among them, the pCS20 real-time PCR TaqMan probe assay provides the best sensitivity with a detection limit of one gene copy per reaction, which is 100 times higher than that 
of conventional pCS20 PCR [20]. However, this assay was reported to cross-react with both $E$. chaffeensis and E. canis [20]. Moreover, although this assay performs well in the sensitive detection and quantification of E. ruminantium, it is not readily transferable to lowtechnology settings where there is limited access to expensive fluorescence detector based thermocyclers.

Loop-mediated isothermal amplification (LAMP) assay is a rapid DNA amplification method originally developed by Notomi et al. [21], and it has been applied for the detection of viral [22,23], bacterial [24,25], fungal [26], and parasitic agents $[27,28]$, but it has never previously been applied to rickettsial agents. The method requires a specially designed primer set that recognizes at least six independent regions of the target gene, which increases the specificity as well as the rapidity of the reaction. LAMP results are visualized by turbidity that can be seen by the naked eye [29], and optionally by agarose gel electrophoresis or by addition of fluorescent dyes visualized under UV light [30,31]. Since the Bst DNA polymerase used in LAMP allows strand displacement-DNA synthesis, LAMP reactions are performed under isothermal conditions using a simple incubator, such as a water bath or heating block. Furthermore, LAMP reagents are relatively stable for a month, even when stored at $37^{\circ} \mathrm{C}$, which is a warmer temperature than recommended by the manufacturer [32]. With these advantages, LAMP has the potential to be used even in clinical laboratories often poorly equipped, facing problems of constant electricity supply in tropical and sub-tropical countries where heartwater is endemic.

The purpose of the present study was to develop LAMP assays for the detection of E. ruminantium and to evaluate the diagnostic sensitivity and specificity of these assays using a panel of bacterial DNA samples, quantitated plasmid standards, and field samples derived from both animal blood and ticks. The newly developed LAMP assays successfully detected E. ruminantium with rapidity, specificity, and high sensitivity.

\section{Results}

\section{Optimization of LAMP}

The reactions for both pCS20 and $\operatorname{sodB}$ LAMP were performed under isothermal conditions at a range of 58 to $66^{\circ} \mathrm{C}$ using plasmid DNA $\left(10^{6}\right.$ copies per reaction) for $120 \mathrm{~min}$, with monitoring of the turbidity. Although amplifications with the LAMP assays were observed at all temperatures tested, the reactions reached the threshold value $(0.1)$ with the shortest incubation times at $61^{\circ} \mathrm{C}$ for pCS20 and $63^{\circ} \mathrm{C}$ for $\operatorname{sodB}$ (data not shown). No nonspecific amplification was detected for the negative cell culture until after at least 120 min incubation. Thus, subsequent LAMP reactions were conducted at these temperatures for $60 \mathrm{~min}$.

\section{Sensitivity of LAMP assays}

The sensitivities of pCS20 and $\operatorname{sodB}$ LAMP assays are shown in Figure 1A, and $1 \mathrm{~B}$, respectively. A plot of the threshold time versus the log of the initial template copy number showed a linear regression, with statistically significant regression coefficients $\left(R^{2}=0.9725\right.$ for pCS20 and 0.9473 for sodB LAMP). The detection limits for these assays, using a positive turbidity signal as the indicator, were 10 copies for pCS20 and 5 copies for sodB LAMP. Alternative detection methods included agarose gel electrophoresis of the LAMP products, which displayed the typical ladder-like pattern (Figure $1 \mathrm{C}$ and $1 \mathrm{D}$, upper panels), as well as the detection of double stranded LAMP products using Gel-Red (Figure $1 \mathrm{C}$ and 1D, lower panels). With smaller amounts of DNA in triplicate assays, 5 copies of pCS20 was amplified once, with a threshold time of $48.3 \mathrm{~min}$, and 1 copy of $\operatorname{sod} B$ was amplified twice with threshold times of 45.7 and $49.4 \mathrm{~min}$.

\section{Specificity of LAMP assays}

The specificity of pCS20 and $\operatorname{sodB}$ LAMP assays was evaluated by using the genomic DNA of 18 known E. ruminantium isolates and five closely related species of Anaplasmataceae: E. canis, E. chaffeensis, Anaplasma centrale, A. marginale, and A. phagocytophilum. All isolates of E. ruminantium were positive in both LAMP assays, the pCS20 real-time PCR and the pCS20 PCR; whereas the pCS20 PCR was cross-reactive with both E. canis and E. chaffeensis (Table 1).

\section{Inhibitory effect of DNA preparation purified from bovine} blood or ticks

In order to access inhibitory effects of components present in field samples, mixtures of standard plasmid DNA and DNA extracts from bovine blood and Amblyomma variegatum were tested by the LAMP assays. When DNA extracts from bovine blood were added to the templates, both pCS20 and $\operatorname{sodB}$ LAMP could not detect 10 copies in two samples, which is in accordance with real-time PCR (Table 2). When DNA extracts from $A$. variegatum were added to the templates, both pCS20 and $\operatorname{sodB}$ LAMP failed in detecting 10 copies in all five samples, while real-time PCR could detect in four. The pCS20 PCR using the KAPA Blood PCR kit detected more positives than the pCS20 PCR using the AmpliTaq Gold PCR kit in the templates with $10^{2}$ and $10^{3}$ copies (Table 2).

\section{Detection of $E$. ruminantium DNA in field samples}

A total of 140 A. variegatum ticks were collected in 7 sites in Uganda and individually analyzed for the presence of E. ruminantium DNA. Out of 140 ticks, including 96 males and 44 females, 12 ticks (11 male 
A

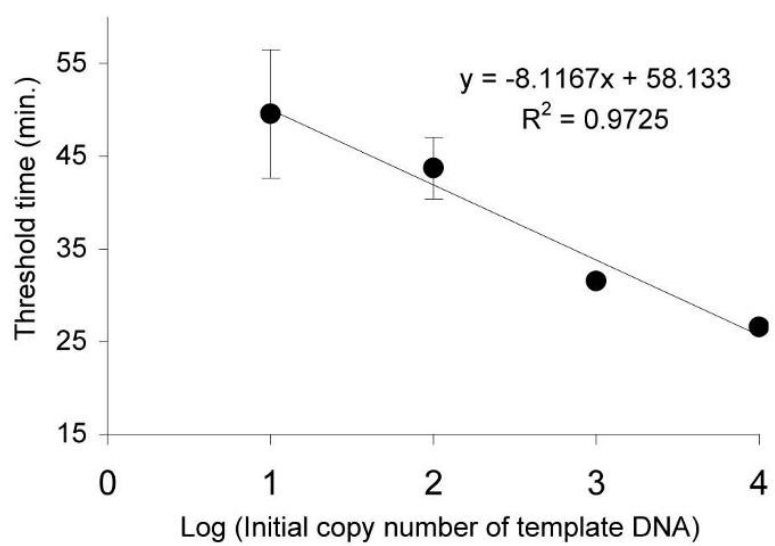

B

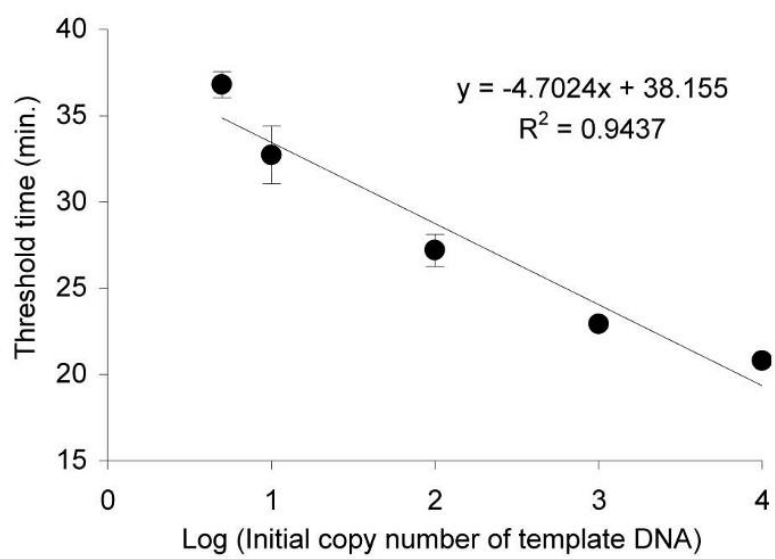

C
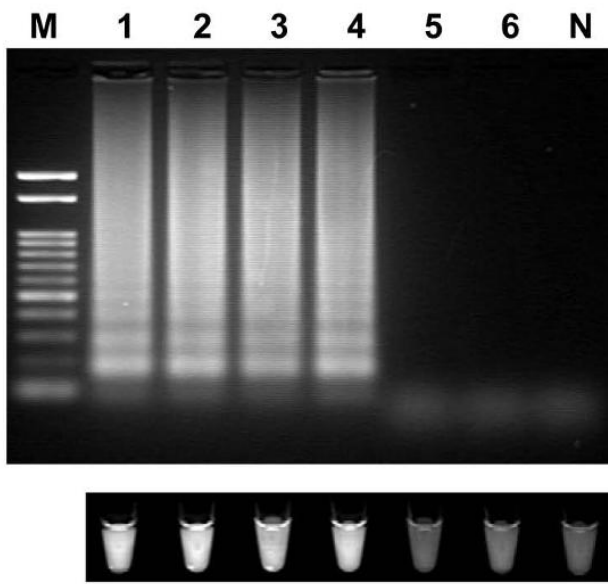

D

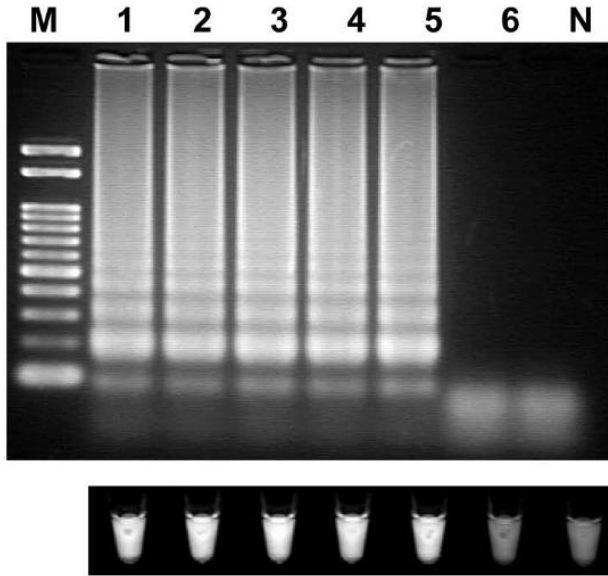

Figure 1 Sensitivities of E. ruminantium LAMP assays. The assays were performed with serial dilutions of plasmid DNA (10 ${ }^{4}, 10^{3}, 10^{2}, 10,5$, and 1 copies per reaction) containing the pCS20 or sodB genes. (A and B) Real-time monitoring of pCS20 (A) and sodB (B) LAMP assays using the Loopamp real-time turbidimeter. Plots represent the mean threshold time (Turbidity of 0.1 ). The error bars represent the standard errors of the mean from three replicates. The plot of the mean threshold time versus the log of the input DNA fit a linear function $\left(R^{2}=0.9725\right.$ for $p C S 20$ LAMP and 0.9437 for sodB LAMP). (C and D) Visual detection of pCS20 (C) and sodB (D) LAMP products. LAMP products were visualized with GelRed TM under UV (lower panel) or electrophoresed in a 2.0\% agarose gel stained with Gel-Red TM (upper panel). Lanes: M, 100-bp molecular weight marker; 1 to 6 , from left to right, $10^{4}$ to 1 gene copy per reaction, as above; $N$, negative control.

and 1 female) were found positive with both pCS20 LAMP and $\operatorname{sodB}$ LAMP. The pCS20 real-time PCR detected 13 positives, including the 12 LAMP-positive ticks and an additional tick from Dokolo, while pCS20 PCR could detect only 8 positives (Table 3 ). All the samples found positive with PCR were also positive with LAMP. The percent positive with LAMP $(8.57 \%)$ was higher than with PCR $(5.71 \%)$ but slightly lower than with real-time PCR (9.29\%). Of the 150 bovine, 35 goat, and 19 lamb blood samples analyzed, two lamb samples were positive using PCR, real-time PCR, and LAMP (Table 3).

\section{Cross-reactivity of LAMP with zoonotic Ehrlichia in the USA}

LAMP assays were conducted with 17 Amblyomma americanum DNA samples from the USA that had previously tested positive for E. chaffeensis, E. ewingii, or PM Ehrlichia (Table 4). Both of the genetic clades of PM Ehrlichia that have been described were represented 
Table 1 Specificities of pCS20 PCR, pCS20 real-time PCR, pCS20 LAMP, and sodB LAMP assays

\begin{tabular}{|c|c|c|c|c|c|c|}
\hline Rickettsial bacteria & Isolate & Origin & pCS20 PCR & pCS20 real-time PCR & pCS20 LAMP & sodB LAMP \\
\hline \multirow[t]{18}{*}{ Ehrlichia ruminantium } & Ball 3 & South Africa & + & + & + & + \\
\hline & Burkina Faso & Burkina Faso & + & + & + & + \\
\hline & Crystal Springs & Zimbabwe & + & + & + & + \\
\hline & Gardel & Guadelope, Caribbean & + & + & + & + \\
\hline & attenuated Gardel & Guadelope, Caribbean & + & + & + & + \\
\hline & Ifé Nigeria & Nigeria & + & + & + & + \\
\hline & Kerr Seringe & Gambia & + & + & + & + \\
\hline & Kiswani & Kenya & + & + & + & + \\
\hline & Kwanyanga & South Africa & + & + & + & + \\
\hline & Lutale & Zambia & + & + & + & + \\
\hline & Pokoase 471 & Ghana & + & + & + & + \\
\hline & Sankat 430 & Ghana & + & + & + & + \\
\hline & São Tomé & São Tomé and Principe & + & + & + & + \\
\hline & Senegal & Senegal & + & + & + & + \\
\hline & attenuated Senegal & Senegal & + & + & + & + \\
\hline & Um Banein & Sudan & + & + & + & + \\
\hline & Welgevonden & South Africa & + & + & + & + \\
\hline & Zeerust & South Africa & + & + & + & + \\
\hline Ehrlichia canis & & & + & - & - & - \\
\hline Ehrlichia chaffeensis & & & + & - & - & - \\
\hline Anaplasma centrale & & & - & - & - & - \\
\hline Anaplasma marginale & & & - & - & - & - \\
\hline Anaplasma phagocytophilum & & & - & - & - & - \\
\hline
\end{tabular}

among these samples. All 17 samples tested negative using both LAMP assays (data not shown).

\section{Discussion}

This report describes the development of two E. ruminantium-specific LAMP assays based on the pCS20 and $\operatorname{sodB}$ genes. The pCS20 region was the first target used for the genetic detection of E. ruminantium [33].
Subsequently, Peter et al. developed a PCR assay targeting pCS20 region with primers AB128 and AB129 for sensitive and specific detection of E. ruminantium [14]. This assay was further evaluated for its reliability by the same authors [15] and has been widely used by many researchers $[12,17,18,34]$. Because primers AB128/129 could not amplify the divergent isolate of Kümm2, van Heerden et al. designed primers HH1F and HH2R in a

Table 2 Inhibitory effects of DNA extracts from field samples on pCS20 PCR, pCS20 real-time PCR, pCS20 LAMP, and sodB LAMP

\begin{tabular}{|c|c|c|c|c|c|c|}
\hline \multirow[b]{2}{*}{ Sample type } & \multirow[b]{2}{*}{$\begin{array}{l}\text { No. of plasmid copies } \\
\text { per reaction }\end{array}$} & \multicolumn{5}{|c|}{ No. of samples: } \\
\hline & & Tested & $\begin{array}{l}\text { pCS20 PCR } \\
\text { positive }\end{array}$ & $\begin{array}{l}\text { pCS20 real-time PCR } \\
\text { positive }\end{array}$ & $\begin{array}{l}\text { pCS20 LAMP } \\
\text { positive }\end{array}$ & $\begin{array}{l}\text { sodB LAMP } \\
\text { positive }\end{array}$ \\
\hline \multirow{5}{*}{$\begin{array}{l}\text { DNA extracts from bovine } \\
\text { blood }\end{array}$} & 1 & 5 & $0(0)^{\mathrm{a}}$ & 0 & 0 & 0 \\
\hline & 10 & 5 & $0(0)$ & 3 & 3 & 3 \\
\hline & $10^{2}$ & 5 & $2(0)$ & 5 & 4 & 5 \\
\hline & $10^{3}$ & 5 & $5(0)$ & 5 & 5 & 5 \\
\hline & $10^{4}$ & 5 & $5(5)$ & 5 & 5 & 5 \\
\hline \multirow{5}{*}{$\begin{array}{l}\text { DNA extracts from Amblyomma } \\
\text { variegatum }\end{array}$} & 1 & 5 & $0(0)$ & 0 & 0 & 0 \\
\hline & 10 & 5 & $0(0)$ & 4 & 0 & 0 \\
\hline & $10^{2}$ & 5 & $5(0)$ & 5 & 5 & 5 \\
\hline & $10^{3}$ & 5 & $5(3)$ & 5 & 5 & 5 \\
\hline & $10^{4}$ & 5 & $5(5)$ & 5 & 5 & 5 \\
\hline
\end{tabular}

${ }^{a}$ Total no. of samples positive by using the KAPA Blood PCR kit (Total no. of samples positive by using the AmpliTaq Gold PCR kit). 
Table 3 Comparison of pCS20 PCR, pCS20 real-time PCR, pCS20 LAMP, and sodB LAMP for the detection of E. ruminantium in various field samples

\begin{tabular}{|c|c|c|c|c|c|c|}
\hline \multirow[b]{2}{*}{ Sample type } & \multirow[b]{2}{*}{$\begin{array}{l}\text { Origin (Site/ } \\
\text { Country) }\end{array}$} & \multicolumn{5}{|c|}{ No. of samples: } \\
\hline & & Tested & $\begin{array}{r}\text { pCS20 PCR } \\
\text { positive } \\
\end{array}$ & $\begin{array}{r}\text { pCS20 real-time PCR } \\
\text { positive }\end{array}$ & $\begin{array}{r}\text { pCS20 LAMP } \\
\text { positive }\end{array}$ & $\begin{array}{r}\text { sodB LAMP } \\
\text { positive }\end{array}$ \\
\hline \multirow[t]{3}{*}{ Bovine blood } & Butaleja/Uganda & 50 & 0 & $N D^{b}$ & 0 & 0 \\
\hline & Petauke/Zambia & 50 & 0 & ND & 0 & 0 \\
\hline & Serengeti/Tanzania & 50 & 0 & ND & 0 & 0 \\
\hline Goat blood & Chama/Zambia & 35 & 0 & ND & 0 & 0 \\
\hline Lamb's blood & $\begin{array}{l}\text { Kerr Seringe/The } \\
\text { Gambia }\end{array}$ & 19 & 2 & 2 & 2 & 2 \\
\hline Sheep blood ${ }^{c}$ & $N A^{d}$ & 4 & 4 & 4 & 4 & 4 \\
\hline \multirow{8}{*}{$\begin{array}{l}\text { Tick; Amblyomma } \\
\text { variegatum }\end{array}$} & Amuria/Uganda & $20(15 / 5)^{\mathrm{e}}$ & $2(2 / 0)$ & $4(4 / 0)$ & $4(4 / 0)$ & $4(4 / 0)$ \\
\hline & Butaleja/Uganda & $20(18 / 2)$ & 0 & $1(1 / 0)$ & $1(1 / 0)$ & $1(1 / 0)$ \\
\hline & Dokolo/Uganda & $20(12 / 8)$ & $1(1 / 0)$ & $2(2 / 0)$ & $1(1 / 0)$ & $1(1 / 0)$ \\
\hline & $\begin{array}{l}\text { Kaberamaido/ } \\
\text { Uganda }\end{array}$ & $20(14 / 6)$ & 0 & $1(0 / 1)$ & $1(0 / 1)$ & $1(0 / 1)$ \\
\hline & Pallisa/Uganda & $20(10 / 10)$ & $2(2 / 0)$ & $2(2 / 0)$ & $2(2 / 0)$ & $2(2 / 0)$ \\
\hline & Soroti/Uganda & $20(17 / 3)$ & $2(2 / 0)$ & $2(2 / 0)$ & $2(2 / 0)$ & $2(2 / 0)$ \\
\hline & Tororo/Uganda & $20(10 / 10)$ & $1(1 / 0)$ & $1(1 / 0)$ & $1(1 / 0)$ & $1(1 / 0)$ \\
\hline & $\begin{array}{l}\text { Subtotal for tick } \\
\text { samples }\end{array}$ & $140(96 / 44)$ & $8(8 / 0)$ & $13(12 / 1)$ & $12(11 / 1)$ & $12(11 / 1)$ \\
\hline
\end{tabular}

aPCR was performed using KAPA Blood PCR kit.

${ }^{\mathrm{b}} \mathrm{ND}$, not done.

'Blood samples from sheep experimentally infected with E. ruminantium were used as positive controls.

${ }^{\mathrm{d}} \mathrm{NA}$, not applicable.

${ }^{\mathrm{e}}$ Total no. of ticks (No. of male ticks/No. of female ticks).

Table 4 Collection details for 17 A. americanum from the USA harboring DNA from Ehrlichia species

\begin{tabular}{|c|c|c|c|c|}
\hline Ehrlichia detected $^{\mathrm{a}}$ & MAP1 types ${ }^{b}$ & Co-infection with other Ehrlichia & Patient & Tick isolation site \\
\hline \multirow[t]{11}{*}{ Panola Mountain Ehrlichia } & Clade 2 & & 22-year-old female & Kentucky \\
\hline & B180/PMtn & & 52-year-old male & Maryland \\
\hline & B180/PMtn & & 25-year-old male & Maryland \\
\hline & Unknown & Ehrlichia ewingii & 50-year-old male & Maryland \\
\hline & Clade 2 & Ehrlichia chaffeensis & 41-year-old male & New Jersey \\
\hline & PME + Clade 2 & & 46-year-old male & New Jersey \\
\hline & B180/PMtn & & 41-year-old male & New Jersey \\
\hline & B180/PMtn & & 31-year-old male & New Jersey \\
\hline & B180/PMtn & & 46-year-old male & New Jersey \\
\hline & B180/PMtn & & $N^{c}$ & Oklahoma \\
\hline & Unknown & & 25-year-old male & Virginia \\
\hline \multirow[t]{2}{*}{ Ehrlichia chaffeensis } & & & 29-year-old male & Virginia \\
\hline & & & 18-year-old female & South Carolina \\
\hline \multirow[t]{4}{*}{ Ehrlichia ewingii } & & & Male ${ }^{d}$ & Virginia \\
\hline & & & Male & Virginia \\
\hline & & & 36-year-old male & Virginia \\
\hline & & & 34-year-old male & Virginia \\
\hline
\end{tabular}

${ }^{a}$ Ehrlichia species were detected by previously described assays [42,45].

${ }^{\mathrm{b}}$ MAP1 types; B180, Clade 2, PME, and PMtn, represents the phylogenetic clade based on the sequence of Major Antigenic Protein 1 (MAP1) gene [42]. ${ }^{\mathrm{C}} \mathrm{NR}$, not recorded.

${ }^{\mathrm{d}}$ Age was not recorded. 
highly conserved region of pCS20 [16]. However, the major drawback of latter assay was cross-reactivity with closely related bacteria such as E. canis and E. chaffeensis, which were not detected by former assay [14,15]. Although pCS20 real-time PCR was also reported to be cross-reactive with E. canis and E. chaffeensis [20], our study did not give the same results (Table 1 ). This inconsistency may be explained by the differences of sequence in pCS20 region between isolates as observed in E. ruminantium [16]. Thus, in this study, we have developed LAMP assays based on not only pCS20 but also $\operatorname{sod} B$ because of its high degree of conservation among isolates.

The pairwise sequence identities calculated for pCS20 showed that the lowest pairwise identity for pCS20 sequences was $83.95 \%$ (between Kümm1 and Kümm2 isolates), whereas that the lowest pairwise identity for the more conserved $\operatorname{sodB}$ gene was $99.00 \%$ (between Senegal and Kümm2 isolates) [35]. This implies that $\operatorname{sod} B$ might be a more suitable target than pCS20 for the genetic detection of this species. Compared to the sequence of Welgevonden isolate, the Kümm2 differs by 24 out of $187 \mathrm{bp}$ in the region targeted by the pCS20 LAMP, while there is no sequence difference in the region targeted by $\operatorname{sodB}$ LAMP (Figure 2). Although both pCS20 and $\operatorname{sodB}$ LAMP detected all the E. ruminantium isolates tested in the present study, $\operatorname{sod} B$ LAMP is more likely to detect previously unknown, divergent isolates of E. ruminantium. Thus, we concluded that $\operatorname{sodB}$ LAMP is more suitable for detecting E. ruminantium and the diagnosis will be made more reliable in combination with pCS20 LAMP.

The detection limits of the pCS20 and $\operatorname{sodB}$ LAMP assays were 10 and 5 copies per reaction, respectively, which are at least 10-times more sensitive than that of conventional pCS20 PCR but slightly less sensitive than pCS20 real-time PCR [20]. According to the instructions for LAMP primer design software, the stability of primer end, especially 5' end of F1c/B1c and 3' end of F2/B2 as well as F3/B3, is one of the crucial factors for designing proper LAMP primers http://loopamp.eiken.co.jp/e/ lamp/primer.html. When LAMP primers were designed for conserved pCS20 regions within isolates, only limited number of primer candidates were obtained initially (data not shown). Therefore, we had to change the optimal values of parameters in the software for further designing pCS20 LAMP primers. In fact, an index for stability of primer, the $\mathrm{dG}$ value of the 5 ' end of the pCS20 B1c region $(-3.69 \mathrm{kcal} / \mathrm{mol})$, is above the value recommended by manufactures $(<-4.00 \mathrm{kcal} / \mathrm{mol})$, which may explain lower sensitivities of pCS20 LAMP than $\operatorname{sodB}$ LAMP.

As is documented in several reports [24,36], LAMP showed relative tolerance to PCR inhibitors in blood, which was comparable to pCS20 real-time PCR (Table 2). However, LAMP was clearly inhibited when DNA extracts from $A$. variegatum were included in the reaction (Table 2). It is known that Amblyomma tick tissue contains PCRinhibitory elements which cannot be always removed during DNA purification $[14,15]$. Thus, LAMP is slightly less sensitive in the presence of such inhibitors in ticks compared to real-time PCR. However, considering that realtime PCR is time-consuming and requires a thermal cycler with real-time monitoring and data analysis systems, which is expensive and can be relatively complicated to use, LAMP has clear advantages over real-time PCR in terms of a practical system in a standard diagnostic laboratory, especially those in developing countries where the disease is prevalent.

In the present study, two sheep blood samples from a heartwater-endemic area tested positive by LAMP (Table 3). Domestic ruminants are known to occasionally harbor E. ruminantium without any clinical signs and to serve as reservoirs of the disease after recovery [37]. Previous reports demonstrated that PCR assays could detect the pathogen in the peripheral blood of clinically healthy animals in heartwater endemic areas $[20,38]$, indicating that a DNA-based technique is useful even for the diagnosis of latent infection. Hence, LAMP is a powerful tool not only for the epidemiological study of heartwater but also for the rapid and sensitive diagnosis of infected animals in the disease-endemic areas.

The simplest way of detecting LAMP products is to inspect the white turbidity that results from magnesium pyrophosphate accumulation, as a by-product of the reaction, by naked eye [29]. However, a small amount of this white precipitate is not always distinguishable from other white precipitates, such as proteins or carbohydrates, derived from the templates. As an alternative method, this study employed a closed system, coupled with a double-stranded DNA (dsDNA)-binding dye, for low-cost detection of amplified DNA (Figure $1 \mathrm{C}$ and $1 \mathrm{D}$, lower panels). The results obtained by this system were consistent with those obtained by gel electrophoresis (Figure 1C and 1D, upper panels). Since the detection can be accomplished in a closed system, without opening the reaction tubes, the risk of contamination is much lower than in gel electrophoresis or by adding dye at the end of the reaction. Theoretically, it should be possible to replace the Gel-Red TM dye we used with other dyes such as SYBR Green I [22,25,39], ethidium bromide, EvaGreen [30], and PicoGreen [40], which are reported to be useful for the detection of LAMP products.

As well documented by Burridge et al., heartwater may easily be introduced into the American mainland through the introduction of infected ticks or animals from heartwater endemic areas [5]. Once imported, it is 
A

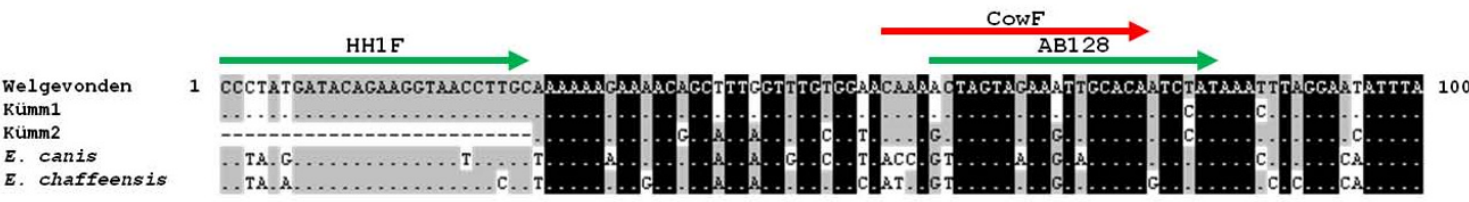

$\boldsymbol{E}$. chaffeensis

TA.A.

Cow $^{\mathrm{m}}$

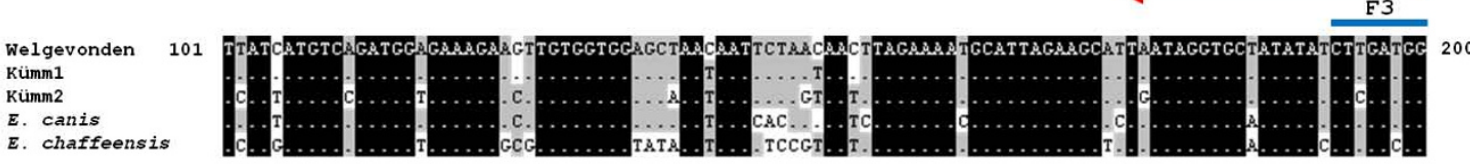

E. can is

E. Chaffeens is

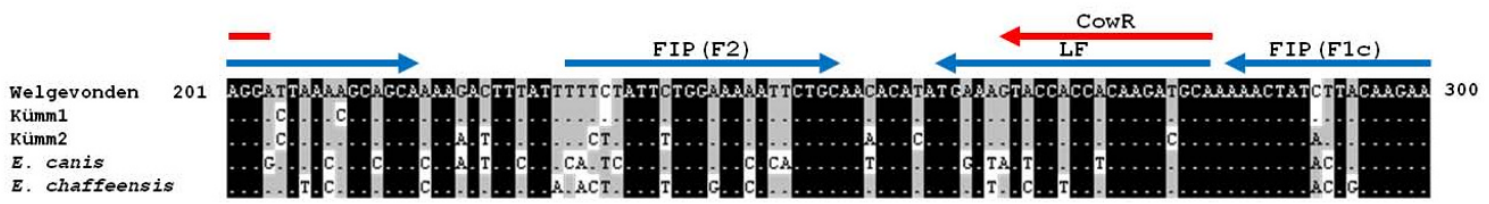

E. Canis

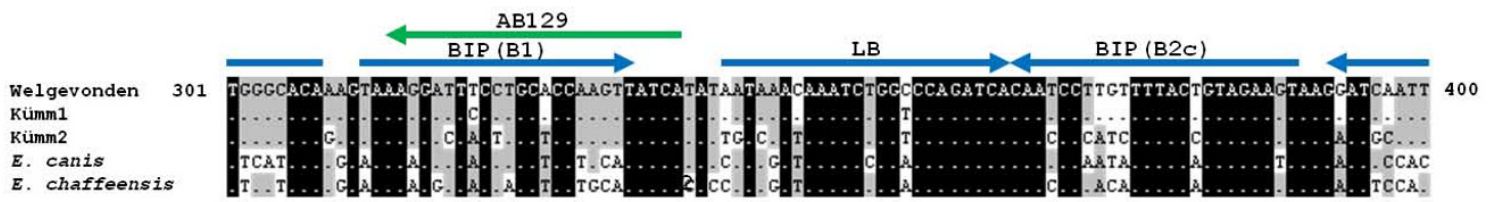

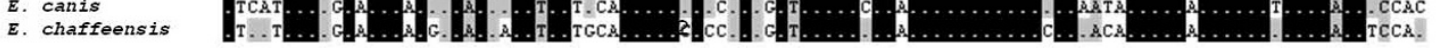

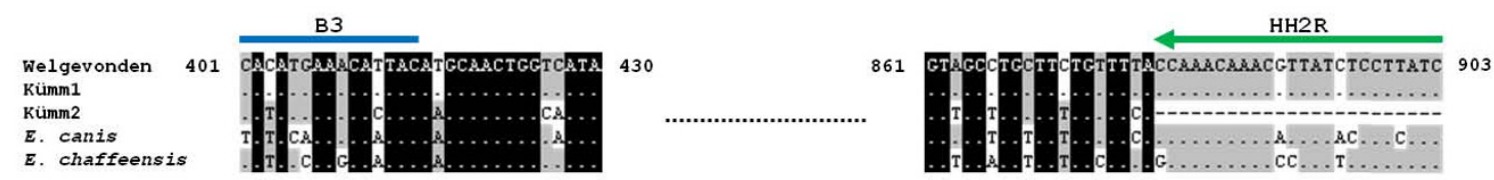

B
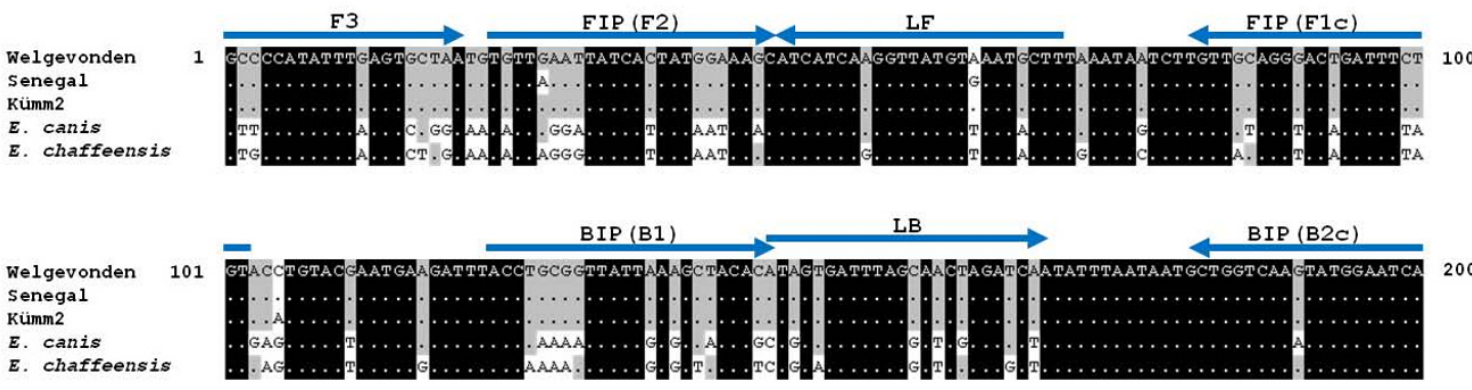

E. chaffeensis

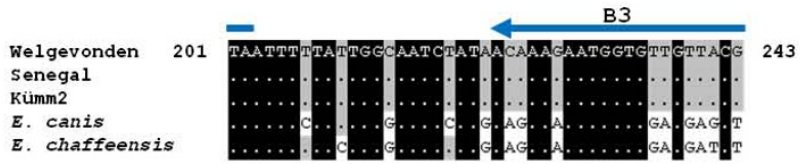

Figure 2 Nucleotide sequence alignment of the target regions of pCS20 (A) and sodB (B) genes. The locations of the primer recognition sites are indicated by arrows, together with the primer names. The blue, green and red arrows represent primers for the LAMP, conventional $P C R$, and real-time $P C R$, respectively. 
likely that the disease could become established because of the presence of local potential tick vectors [5,41]. In order to prevent this pathogen from spreading into the USA, a screening test with high sensitivity and specificity is needed prior to the animal importation. In this respect, the 17 DNA samples from $A$. americanum harboring DNA from Ehrlichia species that are enzootic to the USA were found to be negative in LAMP. Considering that the detection limits of the PCR assay used for the detection of Ehrlichia species in A. americanum were 10 copies per reaction [42], which is comparable to those of LAMP assays, these samples were LAMPnegative not because the DNA concentrations were below the detection levels but probably because there were no cross reactions due to sequence mismatches or deletions in the targeted regions.

\section{Conclusions}

The LAMP assays developed in this study allow rapid, sensitive, and specific detection of E. ruminantium. Although LAMP reactions were inhibited in the presence of extracts from blood and ticks, the diagnostic sensitivity of LAMP was higher than that of conventional PCR, when tested with field-collected ticks. Since LAMP requires minimal time and equipment to perform, this technique can potentially be used in resourcepoor settings where heartwater is endemic. The lack of cross-reactivity with closely related Ehrlichia species enhances its utility for active screening in areas under threat of the introduction of the disease.

\section{Methods}

\section{Rickettsial bacteria}

E. ruminantium isolates used in this study were: Ball 3, Burkina Faso, Crystal Springs, Gardel, attenuated Gardel, Ifé Nigeria, Kerr Seringe, Kiswani, Kwanyanga, Lutale, Pokoase 471, Sankat 430, São Tomé, Senegal, attenuated Senegal, Um Banein, Welgevonden, and Zeerust. Attenuated isolates of Gardel and Senegal were obtained by serial passages in mammalian cells as previously described [43]. All were cultured in bovine aorta endothelial (BAE) cells as described previously [44] and subjected to DNA extraction. Cultures of closely related rickettsia, including $E$. canis, E. chaffeensis, A. centrale, A. marginale, and A. phagocytophilum, were also used for LAMP specificity testing.

\section{Field samples}

From July 2008 to January 2009, adult A. variegatum ticks were collected from indigenous cattle in seven districts in Uganda: Amuria, Butaleja, Dokolo, Kaberamaido, Pallisa, Soroti, and Tororo. Ticks were pooled and stored in sealed plastic bags containing silica gel until DNA extraction. Twenty ticks from each site were randomly selected, and a total of 140 (96 males and 44 females) samples were used in the present study. From July 2008 to May 2009, blood samples were collected from clinically healthy cattle or goats in four different sites in sub-Saharan countries. Bovine blood samples were collected in Butaleja district in Uganda, Serengeti district in Tanzania, and Petauke district in Zambia. Goat blood samples were obtained from Chama district in Zambia. The former two sites are endemic for East Coast fever caused by Theileria parva, and the latter are endemic for trypanosomiosis. These areas are habitats for Amblyomma ticks and lacked adequate tick control programs. In total, 150 bovine blood samples, 50 from each site, and 35 goat blood samples were used in the present study. In addition, this study employed DNA samples extracted from the blood of lambs at Kerr Seringe in the Gambia, where heartwater is endemic. Nineteen samples were randomly selected from those used in the previous study, some of which were positive by pCS20 nested PCR [17]. As positive controls, four blood samples obtained from two sheep experimentally infected with E. ruminantium Senegal isolate were used. Blood was collected from each sheep on days 14 and 16 post infections when the animals showed high fever. Research on samples from animals was conducted adhering to guidelines for Care and Use of Laboratory Animals and was approved by the Animal Care and Use Committee of the Utrecht University.

\section{DNA extraction}

DNAs from rickettsia-infected cell cultures were extracted using Nucleospin Tissue kits (MachereyNagel, Duren, Germany). A. variegatum ticks were washed with $70 \%$ ethanol and rinsed twice with distilled water. Tick samples were then homogenized by Micro Smash MS-100R (TOMY, Tokyo, Japan) for 2 min at 2,500 rpm, followed by DNA extraction with DNAzol (Invitrogen, Carlsbad, CA). DNAs from blood were extracted using either the GenTLE kit (Takara, Shiga, Japan) or a DNA isolation kit for mammalian blood (Roche, Mannheim, Germany). All procedures were carried out as described by the manufacturers.

\section{LAMP primers}

Two sets of LAMP primers were designed for the pCS20 and $\operatorname{sod} B$ genes of E. ruminantium. The nucleotide sequence of the Welgevonden isolate of E. ruminantium was retrieved from GenBank [GenBank:CR767821] and aligned with the available sequences of other isolates to identify conserved regions, using CLUSTALW software version 1.83 (DNA Data Bank of Japan; http://clustalw. ddbj.nig.ac.jp/top-e.html). A potential target region was selected from the aligned sequences, and four primers, comprising two outer (F3 and B3) and two inner (FIP 
Table 5 Primer sets used for LAMP assays in the present study

\begin{tabular}{|c|c|c|c|c|}
\hline Target gene & Primer type & Sequence $\left(5^{\prime}\right.$ to $\left.3^{\prime}\right)$ & Length & Amplicon size with $\mathrm{F} 3+\mathrm{B} 3$ \\
\hline \multirow[t]{6}{*}{ pCS20 } & F3 & CTTGATGGAGGATTAAAAGCA & 21 & 161 \\
\hline & B3 & GTAATGTTTCATGTGAATTGATCC & 24 & \\
\hline & FIP & TGTGCCCATTCTTGTAAGATAGTTT-TTTCTATTCTGGAAAAATTCTGC & 48 & \\
\hline & BIP & TAAAGGATTTCCTGCACCAAGTT-ACTTCTACAGTAAAACAAGGATTG & 47 & \\
\hline & LF & TGCATCTTGTGGTGGTACTTTCA & 23 & \\
\hline & LB & AATAAACAAATCTGGCCCAGATCA & 24 & \\
\hline \multirow[t]{6}{*}{$S O d B$} & F3 & GCCCCATATTTGAGTGCTAA & 20 & 180 \\
\hline & B3 & CGTAACAACACCATTCTTTGT & 21 & \\
\hline & FIP & ACAGAAATCAGTCCCTGCAACA-TGTTGAATTATCACTATGGAAAGC & 46 & \\
\hline & BIP & ACCTGCGGTTATTAAAGCTACACA-TATGATTCCATACTTGACCAGC & 46 & \\
\hline & LF & AAGCATTTACATAACCTTGATGAT & 24 & \\
\hline & LB & ATAGTGATTTAGCAACTAGATCAA & 24 & \\
\hline
\end{tabular}

and BIP) primers, were designed using LAMP primer software PrimerExplorer V4 (http://primerexplorer.jp/ elamp4.0.0/index.html; Eiken Chemical Co., Japan). Loop primers (LF and LB) were designed manually. The designed primer sequences are shown in Table 5 .

\section{LAMP reactions}

LAMP was carried out in a $25-\mu \mathrm{l}$ volume reaction, consisting of $2.5-\mu$ l of $10 \times$ reaction buffer [ $200 \mathrm{mM}$ Tris/ $\mathrm{HCl}$ (pH 8.8), $100 \mathrm{mM} \mathrm{KCl,} 100 \mathrm{mM}\left(\mathrm{NH}_{4}\right)_{2} \mathrm{SO}_{4}, 1 \%$ Tween 20], 3.5- $\mu 110 \mathrm{mM}$ dNTPs, 4.0- $\mu \mathrm{l} 5 \mathrm{M}$ betaine (Sigma, St Louis, MI), $1.5-\mu \mathrm{l} 100 \mathrm{mM} \mathrm{MgSO}_{4}, 2.0-\mu \mathrm{l}$ primer mixture (20 $\mu \mathrm{M}$ each of FIP, BIP, LF, and LB primers, and $2.5 \mu \mathrm{M}$ each of F3 and B3 primers for the PCS20 LAMP; or 20 $\mu \mathrm{M}$ each of FIP, BIP, and LF primers, and $35 \mu \mathrm{M}$ of $\mathrm{LB}$ primers, and $2.5 \mu \mathrm{M}$ each of $\mathrm{F} 3$ and B3 primers for the $\operatorname{sodB} \mathrm{LAMP}$ ), 9.5- $\mu \mathrm{l} \mathrm{DDW}, 1.0-\mu \mathrm{l}$ (8 U) Bst DNA polymerase (New England Biolabs, Beverly, MA), and 1.0- $\mu \mathrm{l}$ template DNA. To find the optimal reaction temperatures for the two LAMP assays, the reaction mixtures were incubated for $120 \mathrm{~min}$ at 58 to $66^{\circ} \mathrm{C}$ in a Loopamp real-time turbidimeter (LA-200; Teramecs, Kyoto, Japan). For the field samples, LAMP reactions were conducted in a heating block.

\section{Preparation of plasmid standard}

The pCS20 and $\operatorname{sodB}$ genes of E. ruminantium were amplified by PCR using the F3 and B3 primers of each LAMP primer set. PCR was carried out using high-fidelity KOD plus DNA polymerase (Toyobo, Tokyo, Japan) in $25-\mu \mathrm{l}$ reaction mixture containing $1.0 \mu \mathrm{M}$ of each primer, $200 \mu \mathrm{M}$ dNTPs, 1.0 unit of KOD plus DNA polymerase, and genomic DNA from E. ruminantium, isolate Welgevonden. Amplification was performed for 25 cycles of $95^{\circ} \mathrm{C}$ for $15 \mathrm{~s}, 55^{\circ} \mathrm{C}$ for $15 \mathrm{~s}$, and $72^{\circ} \mathrm{C}$ for 1 min, followed by a final extension at $72^{\circ} \mathrm{C}$ for $2 \mathrm{~min}$. The PCR products were poly-A tailed and then cloned into a pGEM-T vector (Promega, Madison, WI). Each plasmid clone was sequenced on an ABI Prism 3130 genetic analyzer (Applied Biosystems, Foster City, CA) with BigDye Terminator version 1.1 (Applied Biosystems), to confirm identity, and was used as the standard plasmid for determining the specificity of the respective LAMP assay. The concentrations of plasmid DNA were measured with a Quant-iT dsDNA BR and Qubit Fluorometer (Invitrogen, Carlsbad, CA) and the corresponding copy numbers were calculated.

\section{Assessment of LAMP inhibitors in DNA prepared from blood or ticks}

Five bovine blood samples and five individual $A$. variegatum ticks were obtained from heartwater free areas and verified negative for E. ruminantium by LAMP. Total DNA was extracted as described above. The concentrations of DNA were $0.40-16.56 \mathrm{ng} / \mu \mathrm{l}$ and $1.97-4.20$ $\mathrm{ng} / \mu \mathrm{l}$ for those extracted from bovine blood and $A$. variegatum, respectively. The standard plasmid was diluted with DNA solution prepared from bovine blood or $A$. variegatum to give final concentrations of $1,10,10^{2}$, $10^{3}, 10^{4}$ copies of plasmid DNA per microliter.

\section{LAMP sensitivity and specificity}

The sensitivity of each LAMP assay was assessed using each standard plasmid $\left(10^{4}, 10^{3}, 10^{2}, 10,5\right.$, and 1 copies/reaction) in a Loopamp real-time turbidimeter (Model \& Maker). Readings were analyzed by LA-200 version 0.18 software (Teramecs, Kyoto, Japan), and positive real-time reactions were determined by taking into account the time taken for the turbidity value to increase above a predetermined threshold value of 0.1 [29]. To confirm that each LAMP amplified the correct target, the product was electrophoresed in a $2.0 \%$ agarose gel stained with Gel-Red TM (Biotium, Hayward, CA) or visualized under UV light, as described below. 
LAMP specificity assays were conducted using 18 different isolates of E. ruminantium, isolates of 5 closely related rickettsial bacteria, and tick DNA samples positive for 3 different species of USA ehrlichiae (described below).

\section{Detection of LAMP products}

In addition to monitoring turbidity and gel electrophoresis, we used a common dsDNA-binding dye for the detection of LAMP products. One microliter of the dsDNA-dye mixture, consisting of $25 \%(\mathrm{v} / \mathrm{v})$ glycerol and Gel-Red TM (1:50 dilution of a 10,000× stock solution), was put inside the lid of LAMP reaction tubes. To prevent dye mixture from dripping with vapor, the reaction mixture was overlaid with one drop of mineral oil. After the reaction terminated, the tubes were inverted several times, and LAMP products were visualized under UV light.

\section{PCS20 PCR and pCS20 real-time PCR assays}

To compare the specificity and sensitivity of the LAMP, conventional PCR and real-time PCR to amplify the pCS20 gene was conducted using primers HH1F and HH2R [16], and CowF, CowR and $\operatorname{Cow}^{\mathrm{Tm}}$ probe [20], respectively (Figure 2). PCR was performed with either the KAPA Blood PCR kit (Kapabiosystems, Boston, MA) or the AmpliTaq Gold PCR kit (Applied Biosystem). In order to reduce the effect of PCR inhibitors in the templates, the KAPA Blood PCR kit was used for the analysis of field samples. PCR products were electrophoresed in a $1.2 \%$ agarose gel stained with Gel-Red TM. The real-time PCR was performed with THUNDERBIRD qPCR Mix (Toyobo, Osaka, Japan) and analyzed on Stratagene Mx3000 QPCR System (Stratagene, La Jolla, CA).

\section{A. americanum samples harbouring DNA from Ehrlichia species}

This study employed 17 DNA samples from A. americanum ticks recovered from people in the USA between 2004 and 2006, in which zoonotic Ehrlichia (E. ewingii, E. chaffeensis, or PM Ehrlichia) were detected by conventional PCR for the P28 antigen gene (E. ewingii) or nested PCR based on the 16S rRNA gene (E. chaffeensis) or citrate synthase gene (PM Ehrlichia), as described elsewhere $[42,45]$. Collection details are shown in Table 4.

\footnotetext{
Acknowledgements

The cattle and goat owners are greatly acknowledged for their cooperation We are thankful to all personnel who assisted in collection of field samples in Uganda, Tanzania, and Zambia. We also thank Dr. Amanda Loftis for her facilitating work with the USA ehrlichiae and for her assistance editing this manuscript. The first author was supported by a research grant fellowship from the Japanese Society for the Promotion of Science (JSPS) for young scientists. This work was supported by Grant-in-Aid for JSPS fellows and for Scientific Research from Ministry of Education, Culture, Sports, Science and
}

Technology of Japan (MEXT), the program of Funding Research Center for Emerging and Re-emerging Infectious Disease, MEXT, and Asia-Africa S \& T Strategic Cooperation Promotion Program by the Special Coordination Funds for Promoting Science \& Technology, MEXT.

\section{Author details}

1 Department of Collaboration and Education, Research Center for Zoonosis Control, Hokkaido University, Kita 20, Nishi 10, Kita-ku, Sapporo, Hokkaido 001-0020, Japan. ²Entomological Sciences Program, U.S. Army Public Health Command (Provisional), Aberdeen Proving Ground, Maryland 21010-5403, USA. ${ }^{3}$ National Livestock Resources Research Institute (NaLIRRI), P.O. Box 96, Tororo, Uganda. ${ }^{4}$ International Trypanotolerance Centre, PMB 14, Banjul, The Gambia. ${ }^{5}$ Department of Paraclinical Studies, School of Veterinary Medicine, University of Zambia, P.O. Box 32379, Lusaka, Zambia. ${ }^{6}$ Tsetse \&

Trypanosomiasis Research Institute, P.O. Box 1026, Tanga, Tanzania. ${ }^{7}$ National Research Center for Protozoan Diseases, Obihiro University of Agriculture and Veterinary Medicine, Nishi 2-13, Inada-cho, Obihiro, Hokkaido 080-8555, Japan. ${ }^{8}$ Prince Leopold Institute of Tropical Medicine, Nationalestraat 155, B2000 Antwerp, Belgium. ${ }^{~}$ Utrecht Centre for Tick-borne Diseases (UCTD), Department of Infectious Diseases and Immunology, Faculty of Veterinary Medicine, Utrecht University, Yalelaan 1, 3584CL, Utrecht, The Netherlands. ${ }^{10}$ Department of Veterinary Tropical Diseases, Faculty of Veterinary Science, University of Pretoria, Private Bag X04, 0110, Onderstepoort, South Africa.

${ }^{11}$ Department of Diagnostic Medicine/Pathobiology, College of Veterinary Medicine, Kansas State University, Manhattan, KS 66506, USA.

\section{Authors' contributions}

RN performed LAMP and PCR assays, conducted data analysis, and draft the manuscript. RN, JWM, BN, IM, NI, and CS carried out field sample collections and DNA extractions. EYS, BF, and DG provided DNA samples from lambs or A. americanum. $\mathrm{KK}, \mathrm{JF}$, and CS conceived of the study, and participated in its design and coordination and helped to finalize the manuscript. All authors read and approved the final manuscript.

Received: 14 March 2010 Accepted: 19 November 2010 Published: 19 November 2010

\section{References}

1. Walker JB, Olwage A: The tick vectors of Cowdria ruminantium (Ixodoidea, Ixodidae, genus Amblyomma) and their distribution. Onderstepoort J Vet Res 1987, 54:353-379.

2. Mukhebi AW, Chamboko T, O'Callaghan CJ, Peter TH, Kruska RL, Medley GF, Mahan SM, Perry BD: An assessment of the economic impact of heartwater (Cowdria ruminantium infection) and its control in Zimbabwe. Prev Vet Med 1999, 39:173-189.

3. Allsopp MT, Louw M, Meyer EC: Ehrlichia ruminantium: an emerging human pathogen? Ann N Y Acad Sci 2005, 1063:358-360.

4. Louw M, Allsopp MT, Meyer EC: Ehrlichia ruminantium, an emerging human pathogen-a further report. S Afr Med J 2005, 95:948-950.

5. Burridge MJ, Simmons LA, Peter TF, Mahan SM: Increasing risks of introduction of heartwater onto the American mainland associated with animal movements. Ann N Y Acad Sci 2002, 969:269-274.

6. Anderson BE, Greene CE, Jones DC, Dawson JE: Ehrlichia ewingii sp. nov., the etiologic agent of canine granulocytic ehrlichiosis. Int J Syst Bacteriol 1992, 42:299-302.

7. Buller RS, Arens M, Hmiel SP, Paddock CD, Sumner JW, Rikhisa Y, Unver A, Gaudreault-Keener M, Manian FA, Liddell AM, Schmulewitz N, Storch GA: Ehrlichia ewingii, a newly recognized agent of human ehrlichiosis. $N$ Engl J Med 1999, 341:148-155.

8. Childs JE, Paddock CD: The ascendancy of Amblyomma americanum as a vector of pathogens affecting humans in the United States. Annu Rev Entomol 2003, 48:307-337.

9. Dawson JE, Anderson BE, Fishbein DB, Sanchez JL, Goldsmith CS, Wilson $\mathrm{KH}$, Duntley $\mathrm{CW}$ : Isolation and characterization of an Ehrlichia sp. from a patient diagnosed with human ehrlichiosis. J Clin Microbiol 1991, 29:2741-2745.

10. Perez M, Rikihisa $Y$, Wen B: Ehrlichia canis-like agent isolated from a man in Venezuela: antigenic and genetic characterization. J Clin Microbiol 1996, 34:2133-2139.

11. Rikihisa Y: The tribe Ehrlichieae and ehrlichial diseases. Clin Microbiol Rev 1991, 4:286-308. 
12. Loftis AD, Reeves WK, Spurlock JP, Mahan SM, Troughton DR, Dasch GA, Levin ML: Infection of a goat with a tick-transmitted Ehrlichia from Georgia, U.S.A., that is closely related to Ehrlichia ruminantium. J Vector Ecol 2006, 31:213-223.

13. Reeves WK, Loftis AD, Nicholson WL, Czarkowski AG: The first report of human illness associated with the Panola Mountain Ehrlichia species: a case report. J Med Case Reports 2008, 2:139.

14. Peter TF, Deem SL, Barbet AF, Norval RA, Simbi BH, Kelly PJ, Mahan SM: Development and evaluation of PCR assay for detection of low levels of Cowdria ruminantium infection in Amblyomma ticks not detected by DNA probe. J Clin Microbiol 1995, 33:166-172.

15. Peter T, Barbet A, Alleman A, Simbi B, Burridge M, Mahan S: Detection of the agent of heartwater, Cowdria ruminantium, in Amblyomma ticks by PCR: validation and application of the assay to field ticks. J Clin Microbiol 2000, 38:1539-1544.

16. Van Heerden $H$, Steyn $H C$, Allsopp MT, Zweygarth $E$, Josemans $A$, Allsopp BA: Characterization of the pCS20 region of different Ehrlichia ruminantium isolates. Vet Microbiol 2004, 101:279-291.

17. Faburay B, Geysen D, Munstermann S, Bell-Sakyi L, Jongejan F: Longitudinal monitoring of Ehrlichia ruminantium infection in Gambian lambs and kids by pCS20 PCR and MAP1-B ELISA. BMC Infect Dis 2007, 7:85.

18. Martinez D, Vachiéry N, Stachurski F, Kandassamy $Y$, Raliniaina M, Aprelon R, Gueye A: Nested PCR for detection and genotyping of Ehrlichia ruminantium: use in genetic diversity analysis. Ann N Y Acad Sci 2004, 1026:106-113.

19. Peixoto CC, Marcelino I, Vachiéry N, Bensaid A, Martinez D, Carrondo MJ, Alves PM: Quantification of Ehrlichia ruminantium by real time PCR. Vet Microbiol 2005, 107:273-278.

20. Steyn HC, Pretorius A, McCrindle CM, Steinmann CM, Van Kleef M: A quantitative real-time PCR assay for Ehrlichia ruminantium using pCS20. Vet Microbiol 2008, 131:258-265.

21. Notomi T, Okayama H, Masubuchi H, Yonekawa T, Watanabe K, Amino N, Hase T: Loop-mediated isothermal amplification of DNA. Nucleic Acids Res 2000, 28:E63.

22. Bista BR, Ishwad C, Wadowsky RM, Manna P, Randhawa PS, Gupta G, Adhikari M, Tyagi R, Gasper G, Vats A: Development of a loop-mediated isothermal amplification assay for rapid detection of BK virus. J Clin Microbiol 2007, 45:1581-1587.

23. Parida M, Posadas G, Inoue S, Hasebe F, Morita K: Real-time reverse transcription loop-mediated isothermal amplification for rapid detection of West Nile virus. J Clin Microbiol 2004, 42:257-263.

24. Enosawa M, Kageyama S, Sawai K, Watanabe K, Notomi T, Onoe S, Mori Y, Yokomizo Y: Use of loop-mediated isothermal amplification of the IS900 sequence for rapid detection of cultured Mycobacterium avium subsp. paratuberculosis. J Clin Microbiol 2003, 41:4359-4365.

25. Iwamoto T, Sonobe T, Hayashi K: Loop-mediated isothermal amplification for direct detection of Mycobacterium tuberculosis complex, M. avium, and M. intracellulare in sputum samples. J Clin Microbiol 2003, 41:2616-2622.

26. Inácio J, Flores O, Spencer-Martins I: Efficient identification of clinically relevant Candida yeast species by use of an assay combining panfungal loop-mediated isothermal DNA amplification with hybridization to species-specific oligonucleotide probes. J Clin Microbiol 2008, 46:713-720.

27. Bakheit MA, Torra D, Palomino LA, Thekisoe OM, Mbati PA, Ongerth J, Karanis P: Sensitive and specific detection of Cryptosporidium species in PCR-negative samples by loop-mediated isothermal DNA amplification and confirmation of generated LAMP products by sequencing. Vet Parasitol 2008, 158:11-22.

28. Kuboki N, Inoue N, Sakurai T, Di C, ello F, Grab DJ, Suzuki H, Sugimoto C, Igarashi I: Loop-mediated isothermal amplification for detection of African trypanosomes. J Clin Microbiol 2003, 41:5517-5524.

29. Mori Y, Nagamine K, Tomita N, Notomi T: Detection of loop-mediated isothermal amplification reaction by turbidity derived from magnesium pyrophosphate formation. Biochem Biophys Res Commun 2001, 289:150-154.

30. Qiao YM, Guo YC, Zhang XE, Zhou YF, Zhang ZP, Wei HP, Yang RF, Wang DB: Loop-mediated isothermal amplification for rapid detection of Bacillus anthracis spores. Biotechnol Lett 2007, 29:1939-1946.

31. Tomita N, Mori Y, Kanda H, Notomi T: Loop-mediated isothermal amplification (LAMP) of gene sequences and simple visual detection of products. Nat Protoc 2008, 3:877-882.
32. Thekisoe OM, Bazie RS, Coronel-Servian AM, Sugimoto C, Kawazu S, Inoue N: Stability of Loop-Mediated Isothermal Amplification (LAMP) reagents and its amplification efficiency on crude trypanosome DNA templates. J Vet Med Sci 2009, 71:471-475.

33. Waghela SD, Rurangirwa FR, Mahan SM, Yunker CE, Crawford TB, Barbet AF, Burridge MJ, McGuire TC: A cloned DNA probe identifies Cowdria ruminantium in Amblyomma variegatum ticks. J Clin Microbiol 1991, 29:2571-2577.

34. Faburay B, Geysen D, Munstermann S, Taoufik A, Postigo M, Jongejan F: Molecular detection of Ehrlichia ruminantium infection in Amblyomma variegatum ticks in The Gambia. Exp Appl Acarol 2007, 42:61-74.

35. Allsopp MT, Allsopp BA: Extensive genetic recombination occurs in the field between different genotypes of Ehrlichia ruminantium. Vet Microbiol 2007, 124:58-65.

36. Poon LL, Wong BW, Ma EH, Chan KH, Chow LM, Abeyewickreme W, Tangpukdee N, Yuen KY, Guan Y, Looareesuwan S, Peiris JS: Sensitive and inexpensive molecular test for falciparum malaria: detecting Plasmodium falciparum DNA directly from heat-treated blood by loop-mediated isothermal amplification. Clin Chem 2006, 52:303-306.

37. Andrew HR, Norval RA: The carrier status of sheep, cattle and African buffalo recovered from heartwater. Vet Parasitol 1989, 34:261-266.

38. Semu SM, Peter TF, Mukwedeya D, Barbet AF, Jongejan F, Mahan SM: Antibody responses to MAP $1 \mathrm{~B}$ and other Cowdria ruminantium antigens are down regulated in cattle challenged with tick-transmitted heartwater. Clin Diagn Lab Immunol 2001, 8:388-396.

39. Yoshida A, Nagashima S, Ansai T, Tachibana M, Kato H, Watari H, Notomi T, Takehara T: Loop-mediated isothermal amplification method for rapid detection of the periodontopathic bacteria Porphyromonas gingivalis, Tannerella forsythia, and Treponema denticola. J Clin Microbiol 2005, 43:2418-2424.

40. Tomlinson JA, Barker I, Boonham N: Faster, simpler, more-specific methods for improved molecular detection of Phytophthora ramorum in the field. Appl Environ Microbiol 2007, 73:4040-4047.

41. Barré N, Uilenberg G, Morel PC, Camus E: Danger of introducing heartwater onto the American mainland: potential role of indigenous and exotic Amblyomma ticks. Onderstepoort J Vet Res 1987, 54:405-417.

42. Loftis AD, Mixson TR, Stromdahl EY, Yabsley MJ, Garrison LE, Williamson PC, Fitak RR, Fuerst PA, Kelly DJ, Blount KW: Geographic distribution and genetic diversity of the Ehrlichia sp. from Panola Mountain in Amblyomma americanum. BMC Infect Dis 2008, 8:54.

43. Bekker CP, Postigo M, Taoufik A, Bell-Sakyi L, Ferraz C, Martinez D, Jongejan F: Transcription analysis of the major antigenic protein 1 multigene family of three in vitro-cultured Ehrlichia ruminantium isolates. J Bacteriol 2005, 187:4782-4791.

44. Jongejan F: Protective immunity to heartwater (Cowdria ruminantium infection) is acquired after vaccination with in vitro-attenuated rickettsiae. Infect Immun 1991, 59:729-731.

45. Stromdahl EY, Evans SR, O'Brien JJ, Gutierrez AG: Prevalence of infection in ticks submitted to the human tick test kit program of the U.S. Army Center for Health Promotion and Preventive Medicine. J Med Entomol 2001, 38:67-74.

doi:10.1186/1471-2180-10-296

Cite this article as: Nakao et al:: Development of Loop-Mediated Isothermal Amplification (LAMP) Assays for Rapid Detection of Ehrlichia ruminantium. BMC Microbiology 2010 10:296. 